\title{
Patterns and Severity of Injuries in Patients Following Physical Assault- A Medicolegal Aspects.
}

\author{
Archana Chaudhary ${ }^{1}$, Srijana Kunwar2,Samjhana Ghimire², Harihar Wasti³. \\ ${ }^{1}$ Department of Forensic Medicine, B and C Medical College Teaching Hospital and Research Center, \\ Birtamode, Jhapa, Nepal. \\ ${ }^{2}$ Department of Forensic Medicine, Patan Academy of Health Sciences, Lalitpur, Nepal. \\ ${ }^{3}$ Chief Consultant Forensic Medicine, Government of Nepal.
}

\section{Correspondence:}

Dr. Archana Chaudhary,

Department of Forensic Medicine,

B and C Medical College Teaching Hospital and Research Center, Birtamode, Jhapa.

Email: archiechaudhary@yahoo.com

Phone: +9779801032248

\begin{abstract}
Background and purpose: Physical assault (PA) is a common cause of mortality and morbidity throughout the world and the prevalence is still very high in underdeveloped and developing countries. With the objective to see the spectrum of injury following PA from the medico legal point of view, this study was design in a tertiary care centre at far eastern part of Nepal. Material and method: This is a prospective analytical study with non- probability consecutive sampling of physical assault cases presented in the emergency department over the duration of 4 months. All the patients who meet the inclusion criteria were collected in preformed proforma. Gender, types of weapons used for PA, location of external and internal injuries, various treatment strategies, and severity of injuries were presented in frequencies and percentage. Association of different age categories, gender and types of weapons used with severity of injuries were analysed using Chi square/ Fisher's exact test wherever applicable. Result: There were total 99 patients presented with physical assault during the study period with mean age of presentation 31.69 (SD 13.38) Years with male (70\%) predominance. Among various types of weapons used for PA; punches/ kicks were used in $50 \%$ of assaults followed by blunt heavy objects (35\%) and sharp heavy weapons (14\%). Location of the external injuries were more common in head and neck area. Obvious internal injuries were seen in $14 \%$ of the assaulted patients. Among all the case of PA, $42 \%$ patients needed some sort of surgical intervention during hospital stay. There were $9 \%$ cases of grievous injury and $6 \%$ had life threatening injuries Conclusion: Physical assault is a common mode of injuries in eastern Nepal, where young males are more prone to such injuries. Violence are commonly carried out using fists, kicks and blunt objects. Severity of injuries is similar with all the types of weapons used.
\end{abstract}

Key words: Domestic violence, Grievous, Head injury, Life threatening, Medico-legal, Physical assault.

$\mathrm{P}$ hysical assault (PA) is a common type of domestic violence and is also a common cause of the morbidity and mortality throughout the world which are more common in underdeveloped and developing countries. $^{1-5}$ Among different weapons used in PA; punching, kicking, biting, beating, and attacks with broken glass, knife or gun were the more common. ${ }^{6-8}$ Majority of morbidity/mortality were due to head injuries followed by injuries to the trunk as mention in different literature. ${ }^{8}$ With the objective to see the pattern and severity of the injury following PA from the medico legal point of view, this study was design in a tertiary care centre at far eastern part of Nepal.

16

Date submitted: 05/ 04/2020

Date accepted: 15/05/2020

\section{Material and Methods}

Type of study: Prospective Analytical study

Sampling technique: Non- probability consecutive sampling

Sample size: 99 patients

Duration of study: 4 months (1st April, 2019 to 31st July, 2019)

Site of study: B\&C Medical College Teaching Hospital and Research Centre

\section{Inclusion criteria:}

All the trauma patients admitted at the site of study due to PA. 


\section{Exclusion criteria}

All the patients who were brought dead or died before detail evaluations were completed.

\section{Data collection and analysis:}

The data of all the patients who meet the inclusion criteria were collected in preformed proforma. Age, gender, different types of weapons used, site of external and internal injuries, management strategies, and severity of injury were noted in those proforma.

Age was presented in mean and standard deviation (SD). Gender, types of weapons used for PA, location of external and internal injuries, various treatment strategies, and severity of injuries were presented in frequencies and percentage. Association of different age categories, gender and types of weapons used with severity of injuries were done using Chi square/ Fisher's exact test wherever applicable.

\section{Results}

There were total 99 patients presented with physical assault during the study period with mean age of presentation 31.69 (SD 13.38) Years where majority of them were between 20- 29 years of age (Figure 1). Males (70\%) were predominance in the study sample (Figure 2).

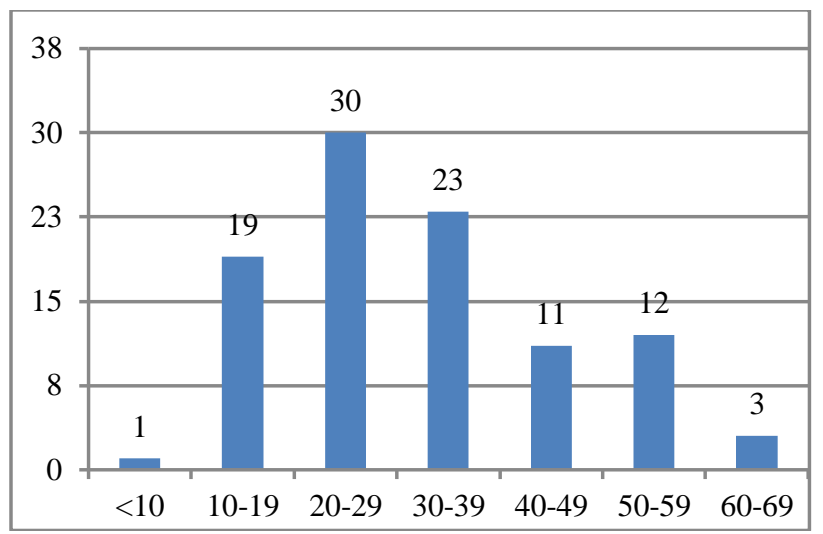

Figure 1: Distribution of different categories of age.

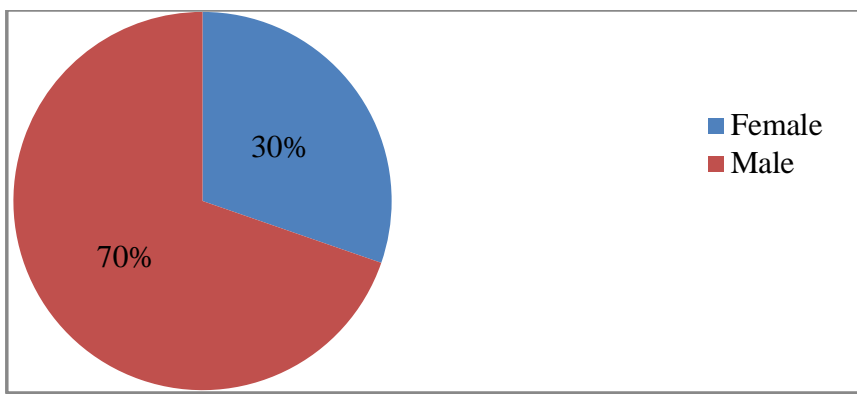

Figure 2: Gender distribution

Among various types of weapons used for PA; punches/ kicks were used in 50\% of assaults followed by blunt heavy objects ( $35 \%$ ) and sharp heavy weapons (14\%) (Figure 3).

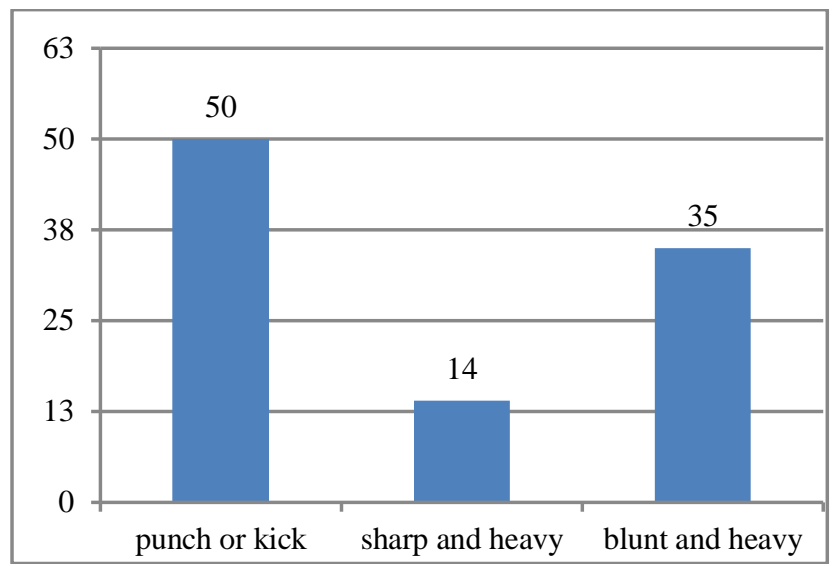

Figure 3: Weapons used for physical assault

Location of the external injuries were more common in head and neck area (67/99) followed by limbs (25/99) and trunk area (11/99) (Figure 4). Obvious internal injuries were seen in $14 \%$ of the assaulted patients where $3 \%$ each were head injury and spinal injury (Figure 5). All the external findings were consistent with the type of weapons used in our study. 


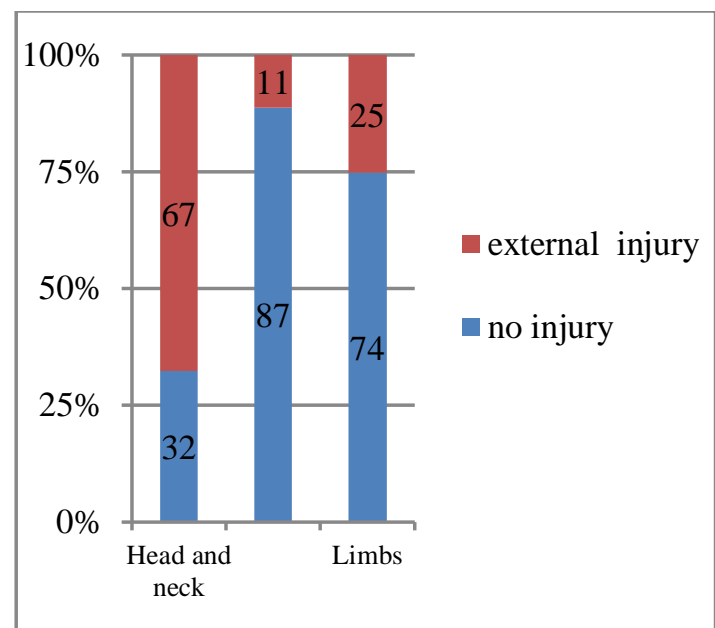

Figure 4: Frequency of external injury in the different parts of body due to physical assault

Among all the case of PA, $42 \%$ patients needed some sort of surgical intervention during hospital stay, where $6 \%$ underwent major surgical intervention (Figure 6).

Medico-legally, all these patients were grouped into simple, grievous, and life threatening injuries. Although, majority of them were simple type of injuries; however, there were $9 \%$ cases of grievous injury and 6\% had life threatening injuries (Table 1). Different categories of age were significantly associated with severity of injury, where age between 20-39 years were more prone to grievous or life threatening injury. Both the genders were equally associated with the different severity of injuries, as the $\mathrm{P}$ value was not significant. Similarly, either of the weapons used during physical assault seems to have similar severity of injuries (Table 2).
Table 1: Distribution of various types of injury as per medico-legal aspects

\begin{tabular}{lrr}
\hline & Frequency & Percent \\
\hline simple & 84 & 84.8 \\
grievous & 9 & 9.1 \\
life threatening & 6 & 6.1 \\
\hline Total & 99 & 100.0 \\
\hline
\end{tabular}

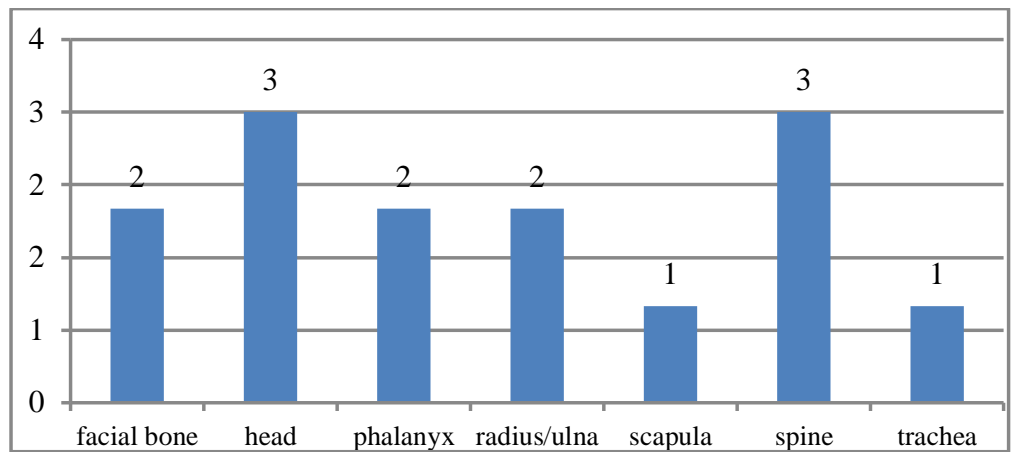

Figure 5: Frequency of major internal injuries following physical assault

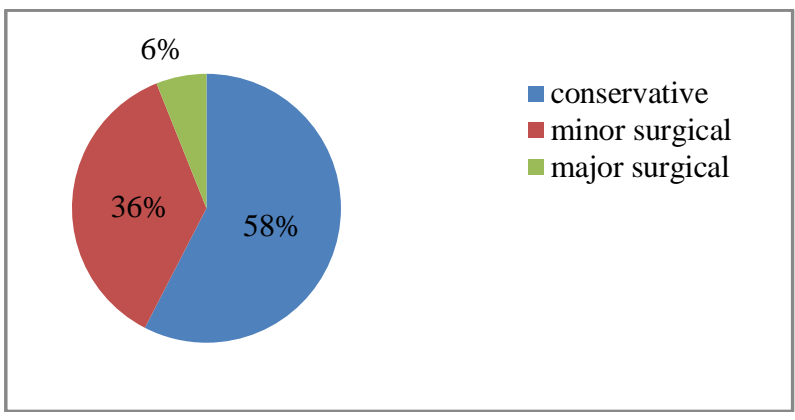

Figure 6: Various treatment provide to the patients

\section{Discussion:}

Physical assault is a manifestation of aggressive mood, and people usually use nearby objects during such violence. ${ }^{8,9}$ Weapons like fist, kicks are usually the most common in early stage followed by blunt objects like stones, bamboo, woods, heavy pots which are easily available in surrounding; hence, are most commonly used weapons. ${ }^{8}$ This seems true in our study as well. Objects like knife, 
khukuri, sickle, are sharp objects commonly found found in our study as well. ${ }^{10,11}$

in Nepal and these were the objects commonly

Table 2: Association of different categories with types of injuries

\begin{tabular}{|c|c|c|c|c|c|c|}
\hline \multicolumn{2}{|c|}{ Different categories } & \multicolumn{3}{|c|}{ Severity of injury } & \multirow[t]{2}{*}{ Total } & \multirow[t]{2}{*}{ P Value } \\
\hline & & simple & grievous & life threatening & & \\
\hline \multirow[t]{7}{*}{ age categories } & $<10$ & 0 & 0 & 1 & 1 & $.031 *$ \\
\hline & $10-19$ & 16 & 1 & 2 & 19 & \\
\hline & $20-29$ & 26 & 4 & 0 & 30 & \\
\hline & $30-39$ & 19 & 1 & 3 & 23 & \\
\hline & $40-49$ & 10 & 1 & 0 & 11 & \\
\hline & $50-59$ & 11 & 1 & 0 & 12 & \\
\hline & $60-69$ & 2 & 1 & 0 & 3 & \\
\hline \multirow[t]{2}{*}{ gender } & Female & 25 & 3 & 2 & 30 & 1.000 \\
\hline & Male & 59 & 6 & 4 & 69 & \\
\hline \multirow[t]{3}{*}{ weapon used } & $\begin{array}{l}\text { punch or } \\
\text { kick }\end{array}$ & 45 & 3 & 2 & 50 & .074 \\
\hline & $\begin{array}{l}\text { sharp and } \\
\text { heavy }\end{array}$ & 9 & 2 & 3 & 14 & \\
\hline & $\begin{array}{l}\text { blunt and } \\
\text { heavy }\end{array}$ & 30 & 4 & 1 & 35 & \\
\hline
\end{tabular}

People aged between 20-40 years are common age group involved in the physical violence and other trauma throughout the world. ${ }^{8,12}$ This might be due to their involvement in outdoor activities where they have to deal with other people of similar age groups. ${ }^{4,5}$ These age groups also seem to get more involved in substance abuse, alcohol abuse, and so the conflicts. ${ }^{1,2}$ In this study, these were same age groups involved in physical assault. Beside them being more common, the nature of injuries were also more significantly associated with more grievous and life threatening in nature.

In physical violence, head is one of the common locations involved and might be due to its easy approach. ${ }^{8,10,11}$ This might also be associated with the intention of assailant. Followed by head, upper limb seems to be the more involved area which might be due to its use in defensive act. ${ }^{10}$

Though most of the external injuries were simple in nature, there was still large number of patients having internal injuries. Among patients having internal injuries around half of them actually required major life saving, or disability preventing surgical intervention. Although, this might be less compared to the road traffic accidents, a significant amount still seems to be affected from physical assault. ${ }^{13,14}$

Medico- legally, the injuries were classified based on severity as simple, grievous, and life threatening. Grievous injuries as classified in the national penal code act 2017 of Nepal includes: ${ }^{15}$ 
a. privation of the sight of either eye,

b. privation of smelling power of nose,

c. privation of hearing power of either ear,

d.privation of speaking power of the tongue,

e. cutting of woman's breast

f. emasculation of man and woman ( making woman infertile or man impotent).

g. privation of the backbone, hand, leg, or joint of such organ by breaking, fracturing dislocating it.

h. any injury which cause the sufferer to be unable to perform his/ her professional work.

Life threatening injuries are not well descried in the national penal code act 2017 of Nepal but as described in previous literatures are those injuries with eminent risk of the death if treatment is not received promptly. ${ }^{16}$ Which includes the cases like traumatic brain injuries, skull fractures, and so on.

Though simple injuries were common in our study, there was still significant population having grievous or life threatening injuries. Males were common in this study; however, in either of the gender the severity of injuries were similar. Similarly, either of the weapons like punch, or kicks, blunt heavy object and sharp heavy object have similar severity of injuries in terms of simple, grievous or life threatening.

\section{Conclusion:}

Physical assault is a common mode of injuries in eastern Nepal, where young males are more prone to such injuries. Violence are commonly carried out using fists, kicks, blunted heavy objects and sharp heavy objects. Severity of injuries were similar with all the types of weapons used. Administration of justice will be prevailed if detailed examination and its interpretation is performed in cases of physical assault in medicolegal terms.

\section{Reference:}

1. Angelucci M. Love on the Rocks: Alcohol abuse and domestic violence in rural Mexico.
2. Bhatt RV. Domestic violence and substance abuse. International Journal of Gynecology \& Obstetrics. 1998 Dec;63:S25-31.

3. Koenig MA, Lutalo T, Zhao F, Nalugoda F, WabwireMangen F, Kiwanuka N, Wagman J, Serwadda D, Wawer M, Gray R. Domestic violence in rural Uganda: evidence from a community-based study. Bulletin of the world health organization. 2003;81:53-60.

4. Canavire-Bacarreza GJ, Rios Avila F. Domestic violence and labor market outcomes: Evidence from a mixed-race developing country.

5. Cramer C. Unemployment and participation in violence.

6. Straus MA, Gelles RJ. Societal change and change in family violence from 1975 to 1985 as revealed by two national surveys. Journal of Marriage and the Family. 1986 Aug 1:465-79.

7. Berrios DC, Grady D. Domestic violence. Risk factors and outcomes. Western Journal of Medicine. 1991

Aug;155(2):133.

8. Brink O, Vesterby A, Jensen J. Pattern of injuries due to interpersonal violence. Injury. 1998 Oct 1;29(9):705-9.

9. Ellis T. Psychopathy as a cause of violent crime in South Africa: a study into the etiology, prevelance and treatment of psychopathy as a cause of violence with particular reference to domestic violence in South Africa (Doctoral dissertation).

10. Karn A, Jha S, Yadav BK, Thakur D. Medico-legal study of suspected homicide cases in a Teaching Hospital in Eastern Nepal. Health Renaissance. 2011;9(1):15-9.

11. Subba SH, Binu VS, Menezes RG, Kumar V, Rana MS. Physical assault related injuries in Western Nepal-a hospital based retrospective study. Journal of forensic and legal medicine. 2010 May 1;17(4):203-8.

12. Yadav AK, Rajbanshi JN, Kushwaha SK, Nepal PR. Prevalence of Head Injury of Patients Arriving in a Tertiary Care Center. Eastern Green Neurosurgery. 2020 Jan 29;2(1):38-41.

13. Krug EG, Mercy JA, Dahlberg LL, Zwi AB. The world report on violence and health. The lancet. 2002 Oct 5;360(9339):1083-8.

14.Briceño-León R, Villaveces A, Concha-Eastman A. Understanding the uneven distribution of the incidence of homicide in Latin America. International journal of epidemiology. 2008 Aug 1;37(4):751-7.

15. Offences Relating to Hurt and Grievous Hurt. The national penal code act 2017 of Nepal. 2017: 122-7.

16. Chaudhary A, Wasti H. Patterns and Severity of Injuries in Patients Following Road Traffic Accidents-A Medicolegal Aspects. Eastern Green Neurosurgery. 2020 Jan 29;2(1):13-7. 